Pak. j. sci. ind. res. Ser. A: phys. sci. 201356 (1) 24-29

\title{
Forbidden Transitions for Low-Lying Levels in Atomic Boron
}

\author{
Gülay Günday Konan ${ }^{a}$, Betül Karaçoban ${ }^{a}$, Güldem Ürer ${ }^{a}$, Leyla Özdemir ${ }^{a *}$ and Osman Ăgar ${ }^{b}$ \\ ${ }^{a}$ Department of Physics, Sakarya University, Sakarya, Turkey \\ ${ }^{b}$ Department of Physics, Karamanoglu Mehmetbey University, Karaman, Turkey
}

(received October 18, 2011; revised April 30, 2012; accepted May 2, 2012)

\begin{abstract}
The multiconfiguration Hartree-Fock in the framework of the Breit-Pauli Hamiltonian (MCHF+BP), relativistic Hartree-Fock (HFR), and multiconfiguration Dirac-Fock (MCDF) calculations of the wavelengths, oscillator strengths, and transition probabilities for the magnetic dipole (M1) and electric quadrupole (E2) forbidden transitions between low-lying levels in the atomic boron have been performed. The data for the analysis of forbidden lines in the spectrum is important for the study of the plasma in astrophysical objects and fusion devices. The data for forbidden transitions obtained from this study have been compared with experimental and other theoretical data available in the literature. Moreover, a discussion of these calculations for the boron atom (B I) has been given in view of the MCHF+BP, HFR and MCDF methods.
\end{abstract}

Keywords: boron, forbidden transitions, transition probabilities, oscillator strengths

\section{Introduction}

The data of electric quadrupole (E2) and magnetic dipole (M1) transitions among the levels of the ground configuration can be used for diagnostics of thermonuclear plasmas or for the estimation of the radiative losses in plasmas (Karwowski and Martin, 1991). The boron atom (B I) is an ideal system to be studied. The ground electronic configuration is $1 s^{2} 2 s^{2} 2 p$ with three electrons outside a compact k-shell core. The small numbers of electrons make theoretical calculations simple for the accuracy of results. Astrophysical scientists have focused their attention on identifying the B I lines in the sun spectrum and the solar abundance of B I. As we know, accurate solar abundance determination is based on precise values of transition probabilities (rates) and oscillator strengths. There are many theoretical methods developed to obtain the energy levels and transition probabilities of atoms and ions. Among all the methods, MCHF method or MCHF combined with Breit-Pauli approximation are the ones that are most widely used in calculating energy levels and transition probabilities of atomic boron.

Analysis of boron spectrum was greatly extended by many other studies (these data can be found from NIST website). The electric dipole (E1) and quadrupole (E2), and magnetic dipole(M1) transition parameters for first-row atoms and their isoelectronic ions using multiconfiguration Dirac-Fock programme of Desclaux were performed (Cheng et al., 1979). E2 and M1 transition probabilities for boron were calculated by

*Author for correspondence; E-mail: lozdemir@sakarya.edu.tr using an extended version of MCHF method which includes relativistic effects in the Breit-Pauli approximation (Fischer, 1983). Other interesting comparative data have been published as a part of the IRON project. Galavis et al. (1998) studied the radiative rates for transitions within $\mathrm{n}=2$ complex in several ions of boron isoelectronic sequence $(6 \leq \mathrm{Z} \leq 28)$. The forbidden emission coefficients for intraconfiguration transitions $2 p_{3 / 2} \rightarrow 2 p_{1 / 2}$ along the boron sequence using the relativistic quantum defect orbital (RQDO) method were reported by Charro et al. (2001). Verhey et al. (1987) performed relativistic calculations of the M1 transition between the ${ }^{2} \mathrm{P}_{3}, 2$ levels of the ground-state boron isoelectronic sequence using the multiconfigurational Dirac-Fock extended average level (MCDF-EAL) method. Mina et al. (1981) calculated relativistic of E1 and $\mathrm{M} 1$ transitions between the $\mathrm{J}=1 / 2$ and $3 / 2$ levels of the ground state in the boron isoelectronic sequence. Energy levels, lifetimes, and transition probabilities for transitions between computed levels were reported for the Be-like $(Z=4-12)$ to Ne-like $(Z=10-24)$ sequences (Fischer and Tachiev, 2004). In their work, several forbidden transitions (M1, E2, and M2) were also presented in addition to allowed (E1) transitions. Moreover, in our earlier work we presented an investigation including the level energies and electric dipole transitions for neutral boron (Karaçoban et al., 2011).

In this work, transition parameters have been presented such as wavelengths, oscillator strengths, and transition probabilities (or rates) for magnetic dipole (M1) and electric quadrupole (E2) transitions of low-lying levels 
of the spectrum in neutral boron (B I). The calculations have been performed by MCDF, MCHF and HFR methods (Grant, 2007; Fischer et al., 1997; Cowan, 1981). The configurations considered according to three different methods are given in Table 1 . These configuration sets are represented with A and B in tables. All results obtained from calculations include contributions from various relativistic and correlation effects.

\section{Materials and Methods}

Calculation methods. MCHF, HFR and MCDF. A detailed information for MCHF, HFR, and MCDF can be found in methods of Grant (2007), Fischer et al. (1997) and Cowan (1981), respectively. A brief introduction of these methods is given below.

In the MCHF method, the wave function (or atomic state function, ASF) $\Psi(\gamma$ LS) is expressed as linear combination of configuration state functions (CSFs) $\Phi\left(\gamma_{\mathrm{i}} \mathrm{LS}\right)$,

$$
\Psi(\gamma \text { LS })=\sum_{\mathrm{i}=1}^{\mathrm{M}} \mathrm{c}_{\mathrm{i}} \Phi\left(\gamma_{\mathrm{i}} \mathrm{LS}\right), \sum_{\mathrm{i}=1}^{\mathrm{M}} \mathrm{c}_{\mathrm{i}}^{2}=1
$$

where, $\gamma$ represent electronic configuration. The mixing coefficients $\mathrm{c}_{\mathrm{i}}$ and the one-electron radial wave functions of $\Phi$ are obtained in a self-consistent procedure by optimization of the energy function based on the nonrelativistic Hamiltonian of an atom,

$$
H_{N R}=\sum_{j=1}^{N}\left(\frac{1}{2} \nabla_{j}^{2}-\frac{Z}{r_{j}}\right)+\sum_{j<k} \frac{1}{r_{j k}}
$$

thus capturing correlation effects. The exact solution can be approximated with arbitrary accuracy if enough CSFs in (1) are taken into account. However, this case is constrained by computing capabilities and limits on method used for the expansion. In this method, the relativistic effects were included as a first-order correction to the MCHF approximation by evaluating Breit-Pauli operators (mass correction and Darwin corrections, spin-orbit, spin-other orbit (spin of one electron and orbit of other electron), orbit-orbit, spinspin contact terms) using configuration interaction (CI) method formed by Rudzikas (2007).

The full relativistic generalization of the MCHF approximation is the MCDF method. In this case ASF expansion (1) is replaced by:

$$
\Psi(\gamma J M)=\sum_{r=1}^{M} c_{r} \Phi\left(\gamma_{r} J M\right)
$$

and energy function is based on the Dirac-Coulomb Hamiltonian,

$$
\mathrm{H}_{\mathrm{DC}}=\sum_{\mathrm{j}=1}^{\mathrm{N}}\left(\mathrm{ca}_{\mathrm{j}} \cdot \overrightarrow{\mathrm{p}}_{\mathrm{j}}+\left(\beta_{\mathrm{j}}-1\right) \mathrm{c}^{2}+\mathrm{V}\left(\mathrm{r}_{\mathrm{j}}\right)\right)+\sum_{\mathrm{j}<\mathrm{k}}^{\mathrm{N}} \frac{1}{\mathrm{r}_{\mathrm{jk}}}
$$

where, $\mathrm{V}\left(\mathrm{r}_{\mathrm{j}}\right)$ is the monopole part of the electron-nucleon interaction. In all calculations, nuclear charge distribution was modelled by the two-component Fermi function. In this method, the transverse Breit interaction at the low-frequency limit and the QED corrections (selfenergy and vacuum polarization) are taken.

Table 1. Configurations selected for atomic boron in the calculations

\begin{tabular}{lll}
\hline \hline Levels & Configurations & \\
\cline { 2 - 3 } & $\mathrm{A}$ & $\mathrm{B}$
\end{tabular}

For MCHF calculations

Odd-parity $\quad 2 s^{2} n p(n=2-5), 2 s 2 p n s(n=3-5), 2 s 2 p n d(n=3-4), 2 s^{2} 4 f$

Even-parity $2 s 2 p^{2}, 2 s n s^{2}(n=3-4), 2 s^{2} n d(n=3-4), 2 s n p^{2}(n=3-4), 3 d^{3}$

For HFR calculations

$$
\begin{array}{ll}
\text { Odd-parity } & 2 s^{2} n p(n=2-4), 2 s^{2} n f(n=4-11) \\
\text { Even-parity } & 2 s 2 p^{2}, 2 s^{2} n s(n=3-10), 2 s^{2} n d(n=3-10)
\end{array}
$$

\section{For MCDF calculations}

$$
\begin{array}{ll}
\text { Odd-parity } & 2 \mathrm{~s}^{2} 2 \mathrm{p}, 2 \mathrm{~s}^{2} 3 \mathrm{p}, 2 \mathrm{~s} 2 \mathrm{p} 3 \mathrm{~s} \\
\text { Even-parity } & 2 \mathrm{~s}^{2} 3 \mathrm{~s}, 2 \mathrm{~s}^{2} 3 \mathrm{~d}, 2 \mathrm{~s}^{2} 4 \mathrm{~s}, 2 \mathrm{~s} 2 \mathrm{p}^{2}, 2 \mathrm{~s} 3 \mathrm{~s}^{2}, 2 \mathrm{~s} 3 \mathrm{p}^{2}, 2 \mathrm{~s} 3 \mathrm{~d}^{2}, 2 \mathrm{~s} 4 \mathrm{~s}^{2}
\end{array}
$$

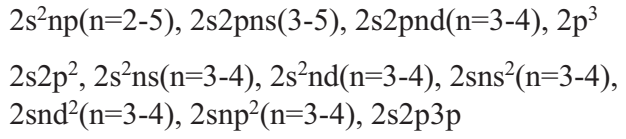

$2 s^{2} n p(n=2-4), 2 s^{2} n f(n=4-6)$

$2 \mathrm{~s} 2 \mathrm{p}^{2}, 2 \mathrm{~s}^{2} \mathrm{~ns}(\mathrm{n}=3-6), 2 \mathrm{~s}^{2} \mathrm{nd}(\mathrm{n}=3-6)$

$2 \mathrm{~s}^{2} 2 \mathrm{p}, 2 \mathrm{~s}^{2} 3 \mathrm{p}, 2 \mathrm{p}^{3}, 3 \mathrm{p}^{3}, 2 \mathrm{~s} 2 \mathrm{p} 3 \mathrm{~s}, 2 \mathrm{~s} 2 \mathrm{p} 3 \mathrm{~d}, 2 \mathrm{~s} 2 \mathrm{p} 4 \mathrm{~s}$

$2 \mathrm{~s}^{2} 3 \mathrm{~s}, 2 \mathrm{~s}^{2} 3 \mathrm{~d}, 2 \mathrm{~s}^{2} 4 \mathrm{~s}, 2 \mathrm{~s} 2 \mathrm{p}^{2}, 2 \mathrm{~s} 3 \mathrm{~s}^{2}, 2 \mathrm{~s} 3 \mathrm{p}^{2}, 2 \mathrm{~s} 3 \mathrm{~d}^{2}$, $2 \mathrm{~s} 4 \mathrm{~s}^{2}, 3 \mathrm{~d}^{3}, 2 \mathrm{~s} 2 \mathrm{p} 3 \mathrm{p}$ 
In the relativistic Hartree-Fock (HFR) method developed by Cowan, the wave function $|\gamma \mathrm{JM}\rangle$ of the M sublevel of a level labelled $\gamma \mathrm{J}$ is expressed in terms of LS basis states $\mid \alpha$ LSJM $\rangle$ by the formula given below:

$$
|\gamma \mathrm{JM}\rangle=\sum_{\alpha \mathrm{LS}}|\alpha \mathrm{LSJM}\rangle\langle\alpha \mathrm{LSJ})|\gamma \mathrm{J}\rangle
$$

The Hamiltonian is also expanded as:

$$
\mathrm{H}=-\sum_{\mathrm{i}} \nabla_{\mathrm{i}}^{2}-\sum_{\mathrm{i}} \frac{2 \mathrm{Z}_{0}}{\mathrm{r}_{\mathrm{i}}}+\sum_{\mathrm{i}>\mathrm{j}} \frac{2}{\mathrm{r}_{\mathrm{ij}}}+\sum_{\mathrm{i}} \zeta_{\mathrm{i}}\left(\mathrm{r}_{\mathrm{i}}\right) \mathrm{i}_{\mathrm{s} \cdot \mathrm{si}}
$$

where, $\zeta(R)=\frac{\alpha^{2}}{2} \frac{1}{r}\left(\frac{\partial V}{\partial r}\right)$ is the spin-orbit term with $\alpha$ the fine structure constant and $\mathrm{V}$ is the mean potential field due to the nucleon and electron. In this method, the mass-velocity and Darwin corrections are included as relativistic contributions.

Radiative properties of atoms are described with an electromagnetic transition between two states and characterized by the angular momentum and parity of the corresponding photon. They are very useful in the fields of quantum electronic, atomic physics and laser spectroscopy, plasma physics and astrophysics. Hence, the reliability of the values of these parameters is mainly based on the performance of the calculation methods used. A detail of theoretical background can be found in literature (Cowan, 1981) or (Grant, 2007). Some formulae have been presented here. Briefly, if the emitted or observed photon has angular momentum $\mathrm{k}$ and parity $\pi=(-1)^{\mathrm{k}}$ the transition is an electric multipole transition $\left(\mathrm{E}^{\mathrm{k}}\right)$, while the transition from absorbed photon with parity $\pi=(-1)^{k+1}$ is magnetic multipole transition $\left(\mathrm{M}^{\mathrm{k}}\right)$.

The transition probability for the emission from the upper level to the lower level is given by:

$$
\mathrm{A}^{\pi \mathrm{k}}\left(\gamma^{\prime} \mathrm{J}^{\prime}, \gamma \mathrm{J}\right)=2 \mathrm{C}_{\mathrm{k}}\left[\alpha\left(\mathrm{E}_{\gamma^{\prime} J^{\prime}}-\mathrm{E}_{\gamma \mathrm{J}}\right)\right]^{2 \mathrm{k}+1} \frac{\mathrm{S}^{\pi \mathrm{k}}\left(\gamma^{\prime} \mathrm{J}^{\prime}, \gamma \mathrm{J}\right)}{\mathrm{g}_{\mathrm{J}^{\prime}}}(7)
$$

where, $\mathrm{S}^{\pi \mathrm{k}}$ is line strength,

$$
\mathrm{S}^{\pi \mathrm{k}}\left(\gamma^{\prime} \mathrm{J}^{\prime}, \gamma \mathrm{J}\right)=\left|<\gamma \mathrm{J}\left\|\mathrm{O}^{\pi(\mathrm{k})}\right\| \gamma^{\prime} \mathrm{J}^{\prime}>\right|^{2}
$$

and $\mathrm{C}_{\mathrm{k}}=(2 \mathrm{k}+1)(\mathrm{k}+1) / \mathrm{k}((2 \mathrm{k}+1) ! !)^{2}$ and $\mathrm{O}^{\pi(\mathrm{k})}$ is transition operator.

The weighted oscillator strength (or gf value) is like the line strength between two levels,

$$
\mathrm{gf}^{\pi \mathrm{k}}\left(\gamma^{\prime} \mathrm{J}^{\prime}, \gamma \mathrm{J}\right)=\mathrm{g}_{\mathrm{J}^{\prime}} \mathrm{f}^{\tau \mathrm{k}}\left(\gamma^{\prime} \mathrm{J}^{\prime}, \gamma \mathrm{J}\right)
$$

where, $g_{J^{\prime}}$ denotes statistical weight of the upper level, namely $\mathrm{g}_{\mathrm{J}^{\prime}}=2 \mathrm{~J}^{\prime}+1$.

\section{Results and Discussion}

The transitions within $\mathrm{n}=2$ complex of boron and boron-like isoelectronic sequence include forbidden and resonance lines which are important in the study of astrophysical and Tokamak plasmas. The corresponding spectral lines are observed in a wide variety of astronomical sources where they are frequently used as temperature, density and abundance diagnostics. The forbidden transitions (M1 and E2) between the $2 s^{2} 2 p-2 s^{2} 2 p$ and $2 s 2 p^{2}-2 s 2 p^{2}$ levels become possible through the fine-structure splitting of LS term into a series of J levels. Fine-structure lines here have been calculated, as they are interesting from a spectroscopic point of view, given their usefulness in spectral analysis in astrophysics and fusion plasma research.

In this study, the transition parameters such as wavelengths, oscillator strengths, and transition probabilities for magnetic dipole (M1) and electric quadrupole (E2) transitions of low-lying levels have been calculated using multiconfiguration Hartree-Fock method within the Breit-Pauli Hamiltonian, $\mathrm{MCHF}+\mathrm{BP}$ given by Fischer et al. (1997), relativistic Hartree-Fock method, HFR given by Cowan (1981) and multiconfiguration Dirac-Fock method including Breit and quantum electrodynamic contributions method, $\mathrm{MCDF}+\mathrm{B}+\mathrm{QED}$ given by Grant (2007), for low-lying states of atomic boron. MCHF code developed by Fischer (2000), Cowan's HFR code downloaded from LANL (2009) website and GRASP code developed by Dyall et al. (1989) based on MCDF method has been used. M1 and E2 transitions combined the states with same parity. The results obtained are reported in Tables 2-4, and compared with other works in tables. In Tables 3-4, the number in brackets represents the power of 10. In these tables, the superscripts A and B represents the calculation results according to the configuration sets considered in Table 1.

Tables 2-4 display the wavelengths, $\lambda(\AA)$, weighted oscillator strengths, $\mathrm{gf}$, and transition probabilities, $\operatorname{Aki}\left(\mathrm{s}^{-1}\right)$, for the magnetic dipole (M1) and electric quadrupole (E2) transitions for $2 s^{2} 2 p-2 s^{2} 2 p$ and $2 s 2 p^{2}-2 s 2 p^{2}$. These levels are low-lying levels of atomic boron. The calculations performed according to three methods mentioned above have included the configuration sets obtained from the excitations outside $1 \mathrm{~s}^{2}$ core. 
Table 2. Wavelengths, $\lambda(\AA)$, for the electric quadrupole(E2) and magnetic dipole(M1) transitions between the low-lying levels in atomic boron

\begin{tabular}{|c|c|c|c|c|c|c|c|c|c|}
\hline \multicolumn{6}{|c|}{ Transitions } & \multicolumn{4}{|c|}{$\lambda(\AA)$} \\
\hline \multicolumn{3}{|c|}{ Lower levels } & \multicolumn{3}{|c|}{ Upper levels } & \multicolumn{3}{|c|}{ This work } & \multirow[t]{2}{*}{ Other works } \\
\hline Conf. & Term & $\mathrm{J}$ & Conf. & Term & $\mathrm{J}$ & $\mathrm{MCHF}+\mathrm{BP}$ & HFR & MCDF & \\
\hline \multicolumn{10}{|c|}{ E2 transitions } \\
\hline $2 s^{2} 2 p$ & ${ }^{2} \mathrm{P}^{\circ}$ & $1 / 2$ & $2 s^{2} 2 p$ & ${ }^{2} \mathrm{P}^{\circ}$ & $3 / 2$ & $\begin{array}{l}6535517.23^{\mathrm{A}} \\
6416790.05^{\mathrm{B}}\end{array}$ & $\begin{array}{l}6438942.73^{A} \\
6535520.55^{B}\end{array}$ & $\begin{array}{l}6540414.50^{\mathrm{A}} \\
8850002.90^{\mathrm{B}}\end{array}$ & $\begin{array}{l}6541500^{\mathrm{a}} \\
6495919.16^{\mathrm{b}}\end{array}$ \\
\hline $2 \mathrm{~s} 2 \mathrm{p}^{2}$ & ${ }^{4} \mathrm{P}$ & $1 / 2$ & $2 \mathrm{~s} 2 \mathrm{p}^{2}$ & ${ }^{4} \mathrm{P}$ & $5 / 2$ & $\begin{array}{l}9744573.60^{\mathrm{A}} \\
10150507.05^{\mathrm{B}}\end{array}$ & $\begin{array}{l}7073569.44^{\mathrm{A}} \\
7976331.66^{\mathrm{B}}\end{array}$ & $\begin{array}{l}3065184.60^{\mathrm{A}} \\
10944733.00^{\mathrm{B}}\end{array}$ & $\begin{array}{l}9120000^{\mathrm{a}} \\
7984164.18^{\mathrm{b}}\end{array}$ \\
\hline $2 \mathrm{~s} 2 \mathrm{p}^{2}$ & ${ }^{4} \mathrm{P}$ & $3 / 2$ & $2 \mathrm{~s} 2 \mathrm{p}^{2}$ & ${ }^{4} \mathrm{P}$ & $5 / 2$ & $\begin{array}{l}18380647.90^{\mathrm{A}} \\
19323844.84^{\mathrm{B}}\end{array}$ & $\begin{array}{l}11321453.26^{\mathrm{A}} \\
12766769.84^{\mathrm{B}}\end{array}$ & $\begin{array}{l}5152553.40^{\mathrm{A}} \\
23279590.00^{\mathrm{B}}\end{array}$ & $\begin{array}{l}15800000^{\mathrm{a}} \\
1492684.66^{\mathrm{b}}\end{array}$ \\
\hline $2 \mathrm{~s} 2 \mathrm{p}^{2}$ & ${ }^{4} \mathrm{P}$ & $1 / 2$ & $2 \mathrm{~s} 2 \mathrm{p}^{2}$ & ${ }^{4} \mathrm{P}$ & $3 / 2$ & $\begin{array}{l}20739929.97^{\mathrm{A}} \\
21382274.11^{\mathrm{B}}\end{array}$ & $\begin{array}{l}18852466.09^{\mathrm{A}} \\
21257343.62^{\mathrm{B}}\end{array}$ & $\begin{array}{l}7566237.10^{\mathrm{A}} \\
20656006.00^{\mathrm{B}}\end{array}$ & $\begin{array}{l}21600000^{\mathrm{a}} \\
17166073.30^{\mathrm{b}}\end{array}$ \\
\hline \multicolumn{10}{|c|}{ M1 transitions } \\
\hline $2 s^{2} 2 p$ & ${ }^{2} \mathrm{P}^{\circ}$ & $1 / 2$ & $2 s^{2} 2 p$ & ${ }^{2} \mathrm{P}^{\circ}$ & $3 / 2$ & $\begin{array}{l}6535517.23^{\mathrm{A}} \\
6416790.05^{\mathrm{B}}\end{array}$ & $\begin{array}{l}6438942.73^{A} \\
6535520.55^{\mathrm{B}}\end{array}$ & $\begin{array}{l}6540414.50^{\mathrm{A}} \\
8850002.90^{\mathrm{B}}\end{array}$ & $\begin{array}{l}6541500^{\mathrm{a}} \\
6495919.16^{\mathrm{b}}\end{array}$ \\
\hline $2 \mathrm{~s} 2 \mathrm{p}^{2}$ & ${ }^{4} \mathrm{P}$ & $3 / 2$ & $2 \mathrm{~s} 2 \mathrm{p}^{2}$ & ${ }^{4} \mathrm{P}$ & $5 / 2$ & $\begin{array}{l}18380647.90^{\mathrm{A}} \\
19323844.84^{\mathrm{B}}\end{array}$ & $\begin{array}{l}11321453.26^{\mathrm{A}} \\
12766769.84^{\mathrm{B}}\end{array}$ & $\begin{array}{l}5152553.40^{\mathrm{A}} \\
23279590.00^{\mathrm{B}}\end{array}$ & $\begin{array}{l}15800000^{\mathrm{a}} \\
1492684.66^{\mathrm{b}}\end{array}$ \\
\hline $2 \mathrm{~s} 2 \mathrm{p}^{2}$ & ${ }^{4} \mathrm{P}$ & $1 / 2$ & $2 \mathrm{~s} 2 \mathrm{p}^{2}$ & ${ }^{4} \mathrm{P}$ & $3 / 2$ & $\begin{array}{l}20739929.97^{A} \\
21382274.11^{B}\end{array}$ & $\begin{array}{l}18852466.09^{A} \\
21257343.62^{\mathrm{B}}\end{array}$ & $\begin{array}{l}7566237.10^{A} \\
20656006.00^{B}\end{array}$ & $\begin{array}{l}21600000^{\mathrm{a}} \\
17166073.30^{\mathrm{b}}\end{array}$ \\
\hline
\end{tabular}

${ }^{\mathrm{a}}$ NIST (2012); ${ }^{\mathrm{b}}$ Fischer and Tachiev (2004).

Table 3. Weighted oscillator strengths, gf, for the electric quadrupole (E2) and magnetic dipole(M1) transitions between the low-lying levels in B I

\begin{tabular}{|c|c|c|c|c|c|c|c|c|c|}
\hline \multicolumn{6}{|c|}{ Transitions } & \multirow{2}{*}{\multicolumn{3}{|c|}{$\begin{array}{c}\text { gf } \\
\text { This work }\end{array}$}} & \multirow{3}{*}{ Other works } \\
\hline \multicolumn{3}{|c|}{ Lower levels } & \multicolumn{3}{|c|}{ Upper levels } & & & & \\
\hline Conf. & Term & $\mathrm{J}$ & Conf. & Term & $\mathrm{J}$ & $\mathrm{MCHF}+\mathrm{BP}$ & HFR & MCDF & \\
\hline \multicolumn{10}{|c|}{ E2 transitions } \\
\hline $2 s^{2} 2 p$ & ${ }^{2} \mathrm{P}^{\circ}$ & $1 / 2$ & $2 s^{2} 2 p$ & ${ }^{2} \mathrm{P}^{\circ}$ & $3 / 2$ & $\begin{array}{l}1.65(-17)^{\mathrm{A}} \\
1.58(-17)^{\mathrm{B}}\end{array}$ & $\begin{array}{l}1.76(-17)^{\mathrm{A}} \\
1.69(-17)^{\mathrm{B}}\end{array}$ & $\begin{array}{l}2.86(-17)^{\mathrm{A}} \\
8.16(-18)^{\mathrm{B}}\end{array}$ & $1.6348(-17)^{\mathrm{a}}$ \\
\hline $2 \mathrm{~s} 2 \mathrm{p}^{2}$ & ${ }^{4} \mathrm{P}$ & $1 / 2$ & $2 \mathrm{~s} 2 \mathrm{p}^{2}$ & ${ }^{4} \mathrm{P}$ & $5 / 2$ & $\begin{array}{l}3.28(-12)^{\mathrm{A}} \\
8.51(-18)^{\mathrm{B}}\end{array}$ & $\begin{array}{l}1.26(-17)^{\mathrm{A}} \\
8.81(-18)^{\mathrm{B}}\end{array}$ & $\begin{array}{l}6.05(-16)^{\mathrm{A}} \\
3.24(-18)^{\mathrm{B}}\end{array}$ & $8.628(-18)^{\mathrm{a}}$ \\
\hline $2 \mathrm{~s} 2 \mathrm{p}^{2}$ & ${ }^{4} \mathrm{P}$ & $3 / 2$ & $2 \mathrm{~s} 2 \mathrm{p}^{2}$ & ${ }^{4} \mathrm{P}$ & $5 / 2$ & $\begin{array}{l}6.67(-13)^{\mathrm{A}} \\
1.78(-18)^{\mathrm{B}}\end{array}$ & $\begin{array}{l}4.31(-18)^{\mathrm{A}} \\
3.01(-18)^{\mathrm{B}}\end{array}$ & $\begin{array}{l}1.78(-16)^{\mathrm{A}} \\
4.71(-19)^{\mathrm{B}}\end{array}$ & $1.8604(-18)^{\mathrm{a}}$ \\
\hline $2 \mathrm{~s} 2 \mathrm{p}^{2}$ & ${ }^{4} \mathrm{P}$ & $1 / 2$ & $2 \mathrm{~s} 2 \mathrm{p}^{2}$ & ${ }^{4} \mathrm{P}$ & $3 / 2$ & $\begin{array}{l}3.90(-14)^{\mathrm{A}} \\
9.81(-20)^{\mathrm{B}}\end{array}$ & $\begin{array}{l}7.41(-20)^{\mathrm{A}} \\
5.18(-20)^{\mathrm{B}}\end{array}$ & $\begin{array}{l}4.47(-18)^{\mathrm{A}} \\
5.36(-20)^{\mathrm{B}}\end{array}$ & $9.706(-20)^{\mathrm{a}}$ \\
\hline \multicolumn{10}{|c|}{ M1 transitions } \\
\hline $2 s^{2} 2 p$ & ${ }^{2} \mathrm{P}^{\circ}$ & $1 / 2$ & $2 s^{2} 2 p$ & ${ }^{2} \mathrm{P}^{\circ}$ & $3 / 2$ & $\begin{array}{l}7.90(-10)^{\mathrm{A}} \\
7.53(-10)^{\mathrm{B}}\end{array}$ & $\begin{array}{l}8.41(-10)^{\mathrm{A}} \\
8.28(-10)^{\mathrm{B}}\end{array}$ & $\begin{array}{l}8.24(-10)^{\mathrm{A}} \\
6.09(-10)^{\mathrm{B}}\end{array}$ & $8.30(-10)^{\mathrm{a}}$ \\
\hline $2 \mathrm{~s} 2 \mathrm{p}^{2}$ & ${ }^{4} \mathrm{P}$ & $3 / 2$ & $2 \mathrm{~s} 2 \mathrm{p}^{2}$ & ${ }^{4} \mathrm{P}$ & $5 / 2$ & $\begin{array}{l}7.32(-10)^{\mathrm{A}} \\
7.92(-10)^{\mathrm{B}}\end{array}$ & $\begin{array}{l}1.29(-9)^{\mathrm{A}} \\
1.14(-9)^{\mathrm{B}}\end{array}$ & $\begin{array}{l}2.82(-9)^{\mathrm{A}} \\
6.25(-10)^{\mathrm{B}}\end{array}$ & $9.752(-10)^{\mathrm{a}}$ \\
\hline $2 \mathrm{~s} 2 \mathrm{p}^{2}$ & ${ }^{4} \mathrm{P}$ & $1 / 2$ & $2 \mathrm{~s} 2 \mathrm{p}^{2}$ & ${ }^{4} \mathrm{P}$ & $3 / 2$ & $\begin{array}{l}6.13(-10)^{\mathrm{A}} \\
6.50(-10)^{\mathrm{B}}\end{array}$ & $\begin{array}{l}7.18(-10)^{\mathrm{A}} \\
6.36(-10)^{\mathrm{B}}\end{array}$ & $\begin{array}{l}1.78(-9)^{\mathrm{A}} \\
6.52(-10)^{\mathrm{B}}\end{array}$ & $7.852(-10)^{\mathrm{a}}$ \\
\hline
\end{tabular}

${ }^{a}$ Fischer and Tachiev (2004); Their gf values were converted from $\mathrm{f}$ values here. 
In HFR calculations, the scaling factors of the Slater parameters $\left(\mathrm{F}^{\mathrm{k}}\right.$ and $\left.\mathrm{G}^{\mathrm{k}}\right)$ and of configuration interaction integrals $\left(\mathrm{R}^{\mathrm{k}}\right)$, not optimized in the least-squares fitting, were chosen equal to 0.85 , while the spin-orbit parameters were left at their ab initio values. This low value of the scaling factor was suggested by Cowan (1981) for neutral elements. The least-squares fitting procedure has not been executed in calculation A.

Table 2 shows wavelengths for the $2 s^{2} 2 p-2 s^{2} 2 p$ and $2 \mathrm{sp}^{2}-2 \mathrm{~s} 2 \mathrm{p}^{2}$ transitions according to MCHF+BP, HFR and MCDF methods. Obtained results have only been compared with (Fischer and Tachiev, 2004) and (NIST, 2012) website. In the work of Fischer and Tachiev, the results have been obtained using MCDHF method. For present studies, different configuration sets were selected from their work and results are often in agreement with other works (NIST, 2012; Fischer and Tachiev, 2004). The ratio ( $\left.\lambda_{\text {our results }} / \lambda_{\text {NIST }}\right)$ has been investigated and this ratio is in range of $0.960-1.163$ and $0.980-1.223$ for $\mathrm{A}$ and $\mathrm{B}$ calculation for MCHF+BP, respectively. For HFR calculation this ratio is in range of 0.717- 0.984 and 0.808-0.999 for A and B calculation, and for MCDF calculation 0.326-0.999 and 0.956-1.473 for A and B calculation, respectively. Therefore there is an agreement between present results and the works of NIST (2012) and Fischer and Tachiev (2004) for wavelengths.

In a similar way ( $\left(\mathrm{gf}_{\text {our results }} / \mathrm{gf}_{\text {other }}\right)$ and ( $\left(\mathrm{Aki}_{\text {our results }} / \mathrm{Aki}_{\text {NIST }}\right)$ have also been investigated for comparing weighted oscillator strengths and transition probabilities values in Tables 3-4, respectively. The ratio of $\left(\mathrm{gf}_{\text {our results }} / \mathrm{gf}_{\text {other }}\right)$ is only compared with results from (Fischer and Tachiev, 2004). This ratio is somewhat poor for A calculation but good for $\mathrm{B}$ calculation performed according to $\mathrm{MCHF}+\mathrm{BP}$. The value of the ratio for $\mathrm{B}$ calculation is in range of 0.812-1.0107. In HFR this ratio for both calculations is better $(0.763-2.316$ for A calculation and $0.810-1.618$ for $\mathrm{B}$ calculation). In MCDF this ratio is poor for A calculation, but somewhat good for B calculation (0.253- 0.830). The ratio ( $\left.\mathrm{Aki}_{\text {our results }} / \mathrm{Aki}_{\mathrm{NIST}}\right)$ is generally good for A calculation according to B calculation (in range of 0.636-2.18) in $\mathrm{MCHF}+\mathrm{BP}$. In HFR this ratio is in range of 1.056-5.343 for A calculation and 1.01-2.929 for $\mathrm{B}$ calculation. This ratio is poor for A calculation, but somewhat good for B calculation in MCDF. These investigations show the degree of accuracy of present results according to calculation methods.

The reason of some differences between the results obtained according to MCHF+BP, HFR, and MCDF

Table 4. Transition probabilities, Aki $\left(\mathrm{s}^{-1}\right)$, for the electric quadrupole(E2) and magnetic dipole(M1) transitions between the low-lying levels in atomic boron

\begin{tabular}{|c|c|c|c|c|c|c|c|c|c|}
\hline \multicolumn{6}{|c|}{ Transitions } & \multicolumn{4}{|c|}{$\operatorname{Aki}\left(\mathrm{s}^{-1}\right)$} \\
\hline \multicolumn{3}{|c|}{ Lower levels } & \multicolumn{3}{|c|}{ Upper levels } & \multicolumn{3}{|c|}{ This work } & \multirow[t]{2}{*}{ Other works } \\
\hline Conf. & Term & $\mathrm{J}$ & Conf. & Term & $\mathrm{J}$ & $\mathrm{MCHF}+\mathrm{BP}$ & HFR & MCDF & \\
\hline \multicolumn{10}{|c|}{ E2 transitions } \\
\hline $2 s^{2} 2 p$ & ${ }^{2} \mathrm{P}^{\circ}$ & $1 / 2$ & $2 s^{2} 2 p$ & ${ }^{2} \mathrm{P}^{\circ}$ & $3 / 2$ & $\begin{array}{l}6.43(-16)^{\mathrm{A}} \\
6.39(-16)^{\mathrm{B}}\end{array}$ & $\begin{array}{l}7.11(-16)^{\mathrm{A}} \\
6.66(-16)^{\mathrm{B}}\end{array}$ & $\begin{array}{l}1.11(-15)^{\mathrm{A}} \\
1.73(-16)^{\mathrm{B}}\end{array}$ & $\begin{array}{l}6.24(-16)^{\mathrm{a}} \\
6.460(-16)^{\mathrm{b}}\end{array}$ \\
\hline $2 \mathrm{~s} 2 \mathrm{p}^{2}$ & ${ }^{4} \mathrm{P}$ & $1 / 2$ & $2 \mathrm{~s} 2 \mathrm{p}^{2}$ & ${ }^{4} \mathrm{P}$ & $5 / 2$ & $\begin{array}{l}9.96(-17)^{\mathrm{A}} \\
3.54(-11)^{\mathrm{B}}\end{array}$ & $\begin{array}{l}2.81(-16)^{\mathrm{A}} \\
1.54(-16)^{\mathrm{B}}\end{array}$ & $\begin{array}{l}7.16(-14)^{\mathrm{A}} \\
3.01(-17)^{\mathrm{B}}\end{array}$ & $\begin{array}{l}7.78(-17)^{\mathrm{a}} \\
1.514(-16)^{\mathrm{b}}\end{array}$ \\
\hline $2 \mathrm{~s} 2 \mathrm{p}^{2}$ & ${ }^{4} \mathrm{P}$ & $3 / 2$ & $2 \mathrm{~s} 2 \mathrm{p}^{2}$ & ${ }^{4} \mathrm{P}$ & $5 / 2$ & $\begin{array}{l}7.00(-18)^{\mathrm{A}} \\
1.98(-12)^{\mathrm{B}}\end{array}$ & $\begin{array}{l}3.74(-17)^{\mathrm{A}} \\
2.05(-17)^{\mathrm{B}}\end{array}$ & $\begin{array}{l}7.46(-15)^{\mathrm{A}} \\
9.67(-19)^{\mathrm{B}}\end{array}$ & $\begin{array}{l}7.00(-18)^{\mathrm{a}} \\
9.282(-18)^{\mathrm{b}}\end{array}$ \\
\hline $2 \mathrm{~s} 2 \mathrm{p}^{2}$ & ${ }^{4} \mathrm{P}$ & $1 / 2$ & $2 \mathrm{~s} 2 \mathrm{p}^{2}$ & ${ }^{4} \mathrm{P}$ & $3 / 2$ & $\begin{array}{l}3.80(-19)^{\mathrm{A}} \\
1.42(-13)^{\mathrm{B}}\end{array}$ & $\begin{array}{l}3.48(-19)^{\mathrm{A}} \\
1.91(-19)^{\mathrm{B}}\end{array}$ & $\begin{array}{l}1.30(-16)^{\mathrm{A}} \\
2.09(-19)^{\mathrm{B}}\end{array}$ & $\begin{array}{l}1.74(-19)^{\mathrm{a}} \\
5.493(-19)^{\mathrm{b}}\end{array}$ \\
\hline \multicolumn{10}{|c|}{ M1 transitions } \\
\hline $2 s^{2} 2 p$ & ${ }^{2} \mathrm{P}^{\circ}$ & $1 / 2$ & $2 s^{2} 2 p$ & ${ }^{2} \mathrm{P}^{\circ}$ & $3 / 2$ & $\begin{array}{l}3.08(-8)^{\mathrm{A}} \\
3.05(-8)^{\mathrm{B}}\end{array}$ & $\begin{array}{l}3.38(-8)^{\mathrm{A}} \\
3.23(-8)^{\mathrm{B}}\end{array}$ & $\begin{array}{l}3.21(-8)^{\mathrm{A}} \\
1.29(-8)^{\mathrm{B}}\end{array}$ & $\begin{array}{l}3.20(-8)^{\mathrm{a}} \\
3.280(-8)^{\mathrm{b}}\end{array}$ \\
\hline $2 \mathrm{~s} 2 \mathrm{p}^{2}$ & ${ }^{4} \mathrm{P}$ & $3 / 2$ & $2 \mathrm{~s} 2 \mathrm{p}^{2}$ & ${ }^{4} \mathrm{P}$ & $5 / 2$ & $\begin{array}{l}2.61(-9)^{\mathrm{A}} \\
2.18(-9)^{\mathrm{B}}\end{array}$ & $\begin{array}{l}1.12(-8)^{\mathrm{A}} \\
7.81(-9)^{\mathrm{B}}\end{array}$ & $\begin{array}{l}1.18(-7)^{\mathrm{A}} \\
1.28(-9)^{\mathrm{B}}\end{array}$ & $\begin{array}{l}4.10(-9)^{\mathrm{a}} \\
4.866(-9)^{\mathrm{b}}\end{array}$ \\
\hline $2 \mathrm{~s} 2 \mathrm{p}^{2}$ & ${ }^{4} \mathrm{P}$ & $1 / 2$ & $2 \mathrm{~s} 2 \mathrm{p}^{2}$ & ${ }^{4} \mathrm{P}$ & $3 / 2$ & $\begin{array}{l}2.52(-9)^{\mathrm{A}} \\
2.23(-9)^{\mathrm{B}}\end{array}$ & $\begin{array}{l}3.37(-9)^{\mathrm{A}} \\
2.35(-9)^{\mathrm{B}}\end{array}$ & $\begin{array}{l}5.18(-8)^{\mathrm{A}} \\
2.55(-9)^{\mathrm{B}}\end{array}$ & $\begin{array}{l}2.23(-9)^{\mathrm{a}} \\
4.444(-9)^{\mathrm{b}}\end{array}$ \\
\hline
\end{tabular}

${ }^{\mathrm{a}}$ NIST (2012); ${ }^{\mathrm{b}}$ Fischer and Tachiev (2004). 
methods is the relativistic contributions of different rank and different valence correlation effects. It is noted that the accuracy of computed wavelengths, oscillator strengths and transition probabilities depends on the line strength and transition energies. But it is clear that more detailed calculations and analyses are required for better comparison of results with the one given in literature.

\section{Conclusion}

In this work the forbidden transitions (electric quadrupole, E2, and magnetic dipole, M1) for the transitions $2 s^{2} 2 p-2 s^{2} 2 p$ and $2 s 2 p^{2}-2 s 2 p^{2}$ has been reported. These lines are not normally allowed by the quantum mechanics selection rules. However, there is a small probability for their spontaneous transitions. Transition parameters are fundamental characteristics of excited states of atoms and ions. They are very useful in various fields of physics such as quantum electronics, laser physics, plasma physics and astrophysics. Consequently, the E2 and M1 transition results obtained using the MCHF, HFR and MCDF methods on atomic boron will be useful in above mentioned including fields of physics and the analysis of boron spectrum.

\section{References}

Charro, E., Lopez-Ferrero, S., Martin, I. 2001. Forbidden emission coefficients for intraconfiguration transitions $2 p_{3 / 2} \rightarrow 2 p_{1 / 2}$ along the boron sequence. Journal of Physics B: Atomic, Molecular, and Optical Physics, 34: 4243-4257.

Cheng, K.T., Kim, Y.K., Desclaux, J.P. 1979. Electric dipole, quadrupole, and magnetic dipole transition probabilities of ions isoelectronic to the first-row atoms, Li through F. Atomic Data and Nuclear Data Tables, 24: 111-189.

Cowan, R.D. 1981. The Theory of Atomic Structure and Spectra, 731 pp., University of California Press, Berkeley, CA, USA.

Dyall, K.G., Grant, I.P., Johnson, C.T., Parpia, F.A., Plummer, E.P. 1989. GRASP: A general-purpose relativistic atomic structure program. Computer Physics Communications, 55: 425-456.

Fischer, C.F., Tachiev, G. 2004. Breit-Pauli energy levels, lifetimes, and transition probabilities for the beryllium-like to neon-like sequences. Atomic Data and Nuclear Data Tables, 87: 1-184.

Fischer, C.F. 2000. The MCHF atomic-structure package. Computer Physics Communications, 128: 635-636.

Fischer, C.F., Brage, T., Jonsson, P. 1997. Computational Atomic Structure, An MCHF Approach, 279 pp., Institute of Physics Publishing, Bristol, UK; and Philadelphia, Penn: Institute of Physics Publ., USA.

Fischer, C.F. 1983. Multiconfiguration Hartree-Fock Breit-Pauli results for ${ }^{2} \mathrm{P}_{1 / 2}-{ }^{2} \mathrm{P}_{3 / 2}$ transitions in the boron sequence. Journal of Physics B: Atomic and Molecular Physics, 16: 157-165.

Galavis, M.E., Mendoza, C., Zeippen, C.J. 1998. Atomic data from the IRON Project. XXIX. Radiative rates for transitions within the $n=2$ complex in ions of the boron isoelectronic sequence. Astronomy and Astrophysics Supplement Series, 131: 499-522.

Grant, I.P. 2007. Relativistic Quantum Theory of Atoms and Molecules, Theory and Computation (Atomic, Optical and Plasma Physics, vol. 40, 797 pp., Springer, New York, USA.

Karaçoban, B., Ozdemir, L., Agar, O., Urer, G. 2011. An investigation on level structure of B I using configuration interaction methods. International Journal of Physics, 4: 43-52.

Karwowski, J., Martin, I. 1991. Quasirelativistic formulation of the quantum-defect-orbital method. Physical Review A, 43: 4832-4836.

LANL. 2009. Los Alamos National Laboratory: http://www.tcd.ie/Physics/People/Cormac.McGui nness/Cowan/), updated version - 2009.

Mina, V.S., Dinh, T.T., Lloyd, Jr.A. 1981. Relativistic study of E1 and M1 transitions in the boron isoelectronic sequence. Physical Review A, 23: 3034-3047.

NIST. 2012. National Institute of Standards and Technology, http://www.nist.gov/physlab/data/ asd.cfm), NIST - Atomic spectra Database (version 5).

Rudzikas, Z. 2007. Theoretical Atomic Spectroscopy, 456 pp., Cambridge University Press, New York, USA.

Verhey, T.R., Das, B.P., Perger, W.F. 1987. Multiconfiguration Dirac-Fock calculation of the forbidden ${ }^{2} \mathrm{P}_{1 / 2} \rightarrow{ }^{2} \mathrm{P}_{3 / 2}$ ground-state M1 transition in the boron isoelectronic sequence. Journal of Physics B: Atomic, Molecular and Optical Physics, 20: 3639-3644. 